\title{
Neuro-Culture Interaction in Specific Brain Region of Immigrants: The Effect of Historical and Current Exposure from the Majority Culture
}

\author{
N.Yusoff $^{1 *}$, N.Samsuri ${ }^{1}$ and F.Reza ${ }^{1}$ \\ ${ }^{1}$ Department of Neurosciences, School of Medical Sciences, Health Campus, Universiti Sains Malaysia, 16150 Kubang
}

Kerian, Kelantan, Malaysia

\begin{abstract}
Ethnic majority culture (i.e. Malay) has given much influence on the biological and psychosocial aspect of immigrants in Malaysia. This study aims to examine the neuro-culture interaction among immigrants (historical and current immigrant) with regards to their emotional response towards Malay cultural heritage visualization. The Event Related Potential technique was used to explore the neural activity of the mental and emotional processes in response to specific culture-related stimuli. A modified oddball paradigm was applied in the presentation of the visual stimulus that was set-up in the e-prime program. Significant neuro-culture interaction was observed in the temporal area (T6) of the brain which was consistent in $\mathrm{P}_{3} 00$ and N2Oo amplitude. Current immigrants indicated significant lower P3Oo and N2OO amplitudes, as compared to majority ethnicity (i.e. Malay). Long- and short-term exposure to cultural environment has an important consequence in the psycho-biological system.
\end{abstract}

Keywords: immigrant; minority ethnic; neuro-culture interaction; emotion; electroencephalography component

\section{INTRODUCTION}

\section{A. The Malaysian - Malay and Ethnic Minority (Historical Immigrant)}

Malaysia is a multi-ethnic and multicultural society that comprises of three main ethnicities. The Malay ethnicity contributes more than $50 \%$ of the Malaysian population, followed by other ethnic minorities - Chinese (25\%) and Indian (7\%) and small percentage of other minority groups (Department of Statistics Malaysia, 2020). Besides Malay being as an ethnic majority in Malaysia, Malays are also known as an ethnic group that is rich with tradition. The Malay tradition is a heritage that is still strong up to this day despite crossing many generations. The strong influence of the Malay tradition can be seen especially in food, clothing, games and even through architecture.

From the Malaysian historical documentation, the existence of Chinese and Indian population in Malaysia is due to the factor of migration that occurred hundreds of years ago. It is believed that the first Chinese and Indian group had migrated to Malaysia around $17^{\text {th }}$ century. Economic factor is the main reason of the migration by which they were hired as labours under the British colonization. Historical documentation also reported that the existence of the Chinese and Indian population in Malaysia (or Tanah Melayu) was due to the practice of intermarriages between Chinese and Indian from mainland and local Chinese and Indian. This scenario has a connection with the strategic location and the popularity of Malacca (one of the states in Peninsular Malaysia, located in Malacca Strait) as a trading centre that encourages merchants (especially Chinese from mainland China and Indian from India) to stop by for trading activities and thus, provided the pathway for the growth of their generation (Othman, 2002; Shafie \& Zainudin, 2000).

Therefore, the growing of the socio-economic status in Tanah Melayu at that time was a motivation for both Chinese and Indian to get used to and infuse the cultural elements of Malay people. This socio-environmental factor has made the 
presence of Chinese and Indian to be always present, continuous and harmonious over generations in Tanah Melayu (Othman, 2002; Shafie \& Zainudin, 2000). It is believed that the fusing of culture between majority and minority had took place in the minority population throughout generations, and even after centuries. The effects that can be seen due to culture fusion between Malay and non-Malay tradition can be seen in various aspects such as communication, clothing, economy, food and even hobbies (Zainal Abidin et al., 2016; Ubaithulla, 2001).

\section{B. Current Immigrant (Non-Malaysian)}

Immigrants are known as a group of people who migrate and live in certain country (outside of their origin country) for a certain duration of time and experience the cultural mixing between their own culture and new settlement culture. Immigrants in Malaysia are a group of non-Malaysians living in Malaysia for various purposes mainly for studying and working (Department of Statistic Malaysia, 2010). The issue of cultural mixing is a popular research area that has been paid much attention since many decades ago. In the field of sociology, this cultural mixing is known as acculturation which describing the long-term process of cultural phenomenon - the process of combining the different cultures in society to form new culture and identity (Ben-Shalom \& Horenczyk, 2003; Cote, 2006). Acculturation is also known as a process of change in beliefs or traditional practices that occurs when a displacement of a cultural system in a group from that of another occurs as a result of the encounter between cultures (Berry, 2005; Sam \& Berry, 2010).

Acculturation has given much impact to immigrants. Strong effects of acculturation can be seen in many aspects of life - food preparation, clothing, communication, hobby and so on. It is also found that, signs of acculturation have been associated not just with changes in daily behavior, but with numerous measures of psychological and physical well-being (e.g. Rosenthal, 2018; Urzua et al., 2017). In addition, with regards to the issue of immigrant and its implication on mental health, numerous recent reports have been documented (e.g. Beiser \& Hou, 2017; Cleary et. al., 2018; Cooper et al., 2019). Meanwhile, some studies that focusing the issue of immigrant from the viewpoint of cultural heritage have found that maintaining the original cultural heritage seems to give positive impact on youth psychosocial adjustment and well-being (Telzer et. al, 2016; Sun et al., 2020). The preference of immigrants towards their own cultural heritage was reported to explain as much as $6 \%$ of the variance of their emotional expression towards the cultural heritage of the new settlement in Malaysia (Yusoff et al., 2019). However, this study is not from an electrophysiological point of view but rather from the questionnaire-based approach in which participants (immigrants) were asked to rate their level of emotional pleasantness while viewing the Malay traditional food.

\section{Neuro-culture Interaction}

Adapting to the culture of other ethnic groups, in fact, is a challenging phase of life among immigrants. Culture indeed is described as an evolutionary dimension (Nichols et al., 2019), thus, implication on the psychological and social dimension of the immigrants greatly expected. According to the model of 'neuro-culture interaction' (Kitayama \& Uskul, 2011; Kitayama \& Tompson, 2010), there are several phases of interaction that take place and contribute to the evolvement of the immigrants' psychosocial dimension. Macro level is the first phase of interaction that need to be pointed out in the migration of the immigrants to Malaysia. In this phase, ecological and societal factors such as climate and social mobility are external factors that influence the process of neuro-culture interaction at macro level. This first phase was followed by the cultural value and task which refers to the cultural practices that are designed to achieve cultural values. In the next phase of the model, it is suggested that repeated exposure in the cultural environment, has led to the formation of culturally patterned neural activities or scientifically known as 'long term potentiation' and thus, making the cultural behaviour spontaneously. The last phase of the model proposes that the interaction of neuron and culture is expected from achieving reputation and identity establishment in local community. As for the outcome of the model (the last phase), the successful of the reproductive should be targeted as a goal in biological adaptation.

This study adopts the neuroscience research tool (i.e. Event Related Potential-ERP) in the study of culture in order to explore the neuro-culture interaction. Throughout the framework of 'neuro-culture interaction', the using of ERP 
technique is able to capture the neural activity of the mental processes, indicated by the very small voltages generated in the brain structures in response to specific cultural related events or stimuli. The ERP is recommended as it provides better understanding of neural mechanism at various cognitive stages in relation to emotion, perception and attention as well as detecting abnormalities in the process of cognition through the exploration of the spatiotemporal features (Woodman, 2010). The oddball paradigm has been used widely in the study of emotion and cognition, especially in exploring the effects of stimulus novelty and its significance in information processing (e.g. Devaney et al., 2019). In the ERP study that applies 3-stimulus oddball paradigm, subjects were presented with a random sequence of visual images where a discrimination task is given in which they reacted to an inconsistently occurring target stimulus embedded into a sequence of frequent standard and rare nontarget stimuli (active task) (Vareka et al., 2014). By using a 3 stimulus oddball paradigm, participants are required to either passively view or behaviourally respond to the less recurring "oddball" stimulus spreaded in a series of more recurring non-target stimulus presentations. The $\mathrm{P} 300$ component is almost always reliably seen by this paradigm as the subject discerns/interprets the "oddball" stimulus (Andreassi, 2007; Polich, 2007). Donchin and Coles (1988) proposed that the $\mathrm{P} 300$ amplitude is evoked as an outcome of context-updating processes in the working memory. The P30o amplitude peaks as a result of mental schema revision upon discerning/interpreting the "oddball" stimulus that does not fit into the existing schema established by the more recurring non-target stimuli. The three-stimulus oddball task is capable of depicting the subcomponents of $\mathrm{P}_{3}$ oo, namely $\mathrm{P}_{3} \mathrm{a}$ and $\mathrm{P}_{3} \mathrm{~b}$, both of which are related but represent different aspects of attentional and cognitive processes (Polich, 2007).

In addition, the using of stimulus novelty in this current study (i.e., the visual images of Malay culture tradition) is underpinned by theoretical support such as Gestalt's theory which suggests that visual perception towards something reflects on the emotional tendency of a person (Koffka, 1935; Kohler, 1938). This fundamental understanding has been established by studies in the field of psychology_that have attempted to understand perception (e.g. Curby \& Moerel,
2019; Dybala et. al., 2020; Feldman, 2001; Guberman, 2017; Kałamała et al., 2017). In fact, humans and animals use visualisation to process information from the environment for survival. This current study applied one of several of Gestalt's principles i.e. the Law of Past Experience which generally suggests that our previous experience influence or guide our thought (perception, judgement) towards image we see. Based on the theory proposed, it can be hypothesized that the emotional response of immigrants towards Malay cultural pictures relies upon their encounters when they are in Malaysia. In other words, the longer they are in Malaysia, the more exposed they are to the Malay culture. 'Neuro-culture interaction' is adopted as a framework to explore the specific neuro-culture question, i.e. how the difference between the historical immigrants and the current immigrants could be explained by the neural mechanism, with regards to the culture of ethnic majority, i.e. Malay.

\section{MATERIALS AND METHOD}

\section{A. Participants}

A total of 120 participants were recruited from Kota Bharu the capital city of Kelantan. They were informed to participate in this study through the advertisement that was distributed in the city. Kelantan is known as one of the states in the east coast of Malaysia that has a settled majority of Malay ethnicity that practices rich elements of Malay tradition. In addition, this city is also known as one of Malaysia's attractive places among tourists and immigrants for vacation, working, and studying. An almost equal proportion of male and female participants involved in this study (Male: 54\%) with age ranged from 18-39 years old (mean age: 27.8 \pm 5.01 ). Participants were divided into 4 groups - (1) Malay ethnic (referral group), (2) historical immigrant (i.e. Malaysian Chinese and Indian), (3) current immigrant 1, i.e. immigrants living in Malaysia for a year and less, (4) current immigrant 2, i.e. immigrants living in Malaysia for more than a year. We used operational definitions to define and describe the two natures of immigrants in Malaysia as stated in Table 1. 
Table 1. Operational definition of immigrants in Malaysia

\begin{tabular}{ll}
\hline \multicolumn{1}{c}{ Term } & \multicolumn{1}{c}{ Description } \\
\hline Historical & Malaysian citizen. \\
Immigrant & $\begin{array}{l}\text { The biggest minority group in } \\
\text { Malaysia - Chinese and Indian who } \\
\text { migrated to Malaysia centuries ago. }\end{array}$ \\
& $\begin{array}{l}\text { Non-Malaysian. } \\
\text { Jurrent }\end{array}$ \\
Immigrant* & various reasons - vacation, working, \\
& studying, family matters and so on.
\end{tabular}

*Current immigrants were classified into two group - (1) those living in Malaysia for a year and less and (2) those living in Malaysia for more than a year.

The group of current immigrants were divided into two groups with the cut-off point of one year because previous studies has reported that the emotional impact on immigrants greatly occurred after a year staying in new settlement (see review by De Leersnyder, 2017). A large proportion of the participants in current immigrant group was from South Asia (42\%) followed by immigrants from West Asia (30\%) and Africa (28\%). More than 90\% of the participants were right-handed and reported to be right eye dominant. Some participants had vision problem; however, the problem was corrected by glasses and contact lenses. Through purposive sampling, participants with uncorrected vision, current or lifetime history of affective disorder, and were born in a mix-marriage family (Malay and Chinese, Malay and Indian, Chinese and Indian) were excluded from the study. In addition, current immigrants who have Malaysian spouses and Malaysian parents (either father or mother or both) have also been excluded from this study to avoid cultural bias in their emotional reaction.

\section{B. Procedure}

Protocol approval and its ethical clearance was obtained from the Human Ethical Committee of Universiti Sains Malaysia (reference number: USM/JEPeM/17090391). A briefing on the objectives of the study were explained before a written consent form was distributed to the participants upon agreement to join the study. The Event Related Potential (ERP) session that involves the electroencephalograph (EEG) recording was held in the Clinical Neuroscience Laboratory, University Hospital.

\section{Visual Stimuli: Malay Culture and Non-Culture Images}

A series of 50 images (i.e. 10 images of Malay cultural heritage, 30 geomatical images and 10 images of universal non-culture) was used as a stimulus during the ERP session to evoke cultural-related emotion that was designed using the E-Prime® 2.0 software. Various type of culture and nonculture images were displayed to the participants, i.e. cloth, food, game, building and tool. In order to minimize the attentional and emotional bias, the selection of picture was done by pairing the cultural image and non-cultural image from the same category. For example, the Malay traditional dress (CULTURAL STIMULI) was paired with a modern dress (NON-CULTURE STIMULI). Meanwhile, geometrical images were used as a control stimulus that classified as nonemotional stimulus. All cultural pictures were declared as 'Malay cultural heritage' as they are listed under the national heritage of Malaysia by the Department of National Heritage, Malaysia (2020). In addition, all pictures used in this study has been made sure to be free from any copyright policy.

The validity of the pictures was established through the content validity assessment that was carried out by two academicians and one cultural officer who are experts in Malay tradition. All three were told to view, rate and determine the presented images whether Malay culture or non-culture based on a 4-point scale (Davis, 1992) as follows $-1=$ not relevant, 2 = somewhat relevant, 3 = quite relevant, and 4 = highly relevant. The content validity of the images was ascertained by the Content Validity Index (CVI). Since all images were determined by the experts to have the value of one for the content validity index for the items (I-CVI), thus, the content of the images was valid enough to be used for the purpose of this study.

\section{ERP Session/EEG Recording}

Upon agreeing to participate in the study and providing a written informed consent, participants provided their sociodemographic data. In order to familiarise the subjects with the ERP procedure, a pre-training session with 10 practice trials was held before either session. Based on the standard protocol provided by Electrical Geodesics, Inc. (EGI), the electrolyte solution was prepared before the EEG recording session. The head circumference of participants was 
measured along the brow ridge or glabella to determine the appropriate EEG net for the size of $56 \mathrm{~cm}$ and $58 \mathrm{~cm}$.

In the ERP session that applied the modified oddball and choice reaction paradigm, participants were asked to view 50 images from three categories of images - Malay cultural heritage (10 different images), universal non-culture (10 images) and geometry images (30 different images) which equals to the ratio of 1:1:3. The ratio of 1:1:3 was adopted in order to be in line with the principle of the oddball paradigm in which the presentation of sequences of repetitive stimuli are infrequently interrupted by a deviant stimulus. Pictures were presented randomly with two times repetition within five blocks which made a total of 100 trials. During the EEG recording, participants viewed a series of images presented to them in a modified oddball paradigm, projected from the computer screen that connected to the EEG recording system. At the same time, they pressed ' 1 ' when they saw a Malay cultural heritage image and pressed ' 2 ' when they saw a universal non-cultural image. No response was required for the geometry images. The visual representation of the oddball task started with the fixation mark (+) for $500 \mathrm{~ms}$ followed by a blank black screen for 8ooms. The appearing of the stimulus images was set up for $2000 \mathrm{~ms}$ in the next screen (Figure 1). The principle of oddball paradigm with randomization was applied for the stimulus images. A similar order was programmed to repeat the presentation of the images. All images were set up to a resolution of 640 pixels $x$ 480 pixels.

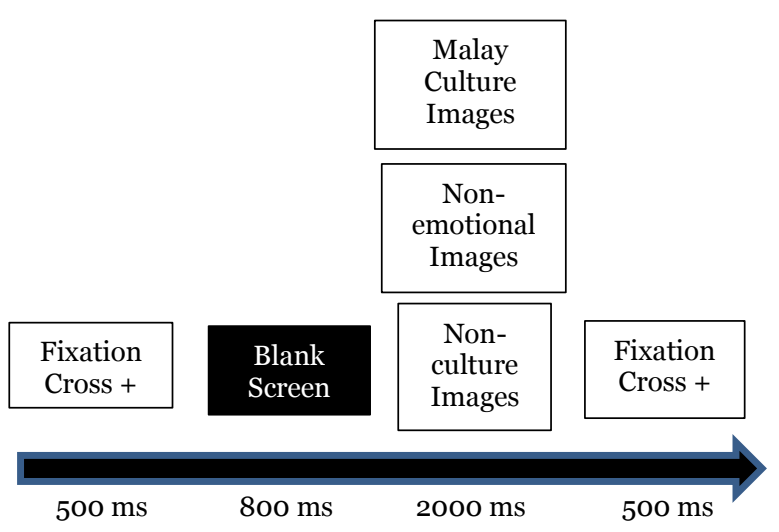

Figure 1. Schematic illustration of the experimental procedure

The 128 HydroCel GSN which was connected to a highinput impedance NetAmps 300 amplifier was used to record the continuous EEG from the brain wave. Digitization of EEG data was done at $250 \mathrm{~Hz}$ with electrodes impedance maintained below $50 \mathrm{k} \Omega$. In the case of high impedance, an improvement was done by dropping the electrolyte solution at the problematic electrode. Other than that, the EEG recording system applied a bandpass range filter of $0.30-$ $50.00 \mathrm{~Hz}$ as well as $50 \mathrm{~Hz}$ Notch with the 100ms pre-stimulus onset and 1000ms post-stimulus onset to lock the segmentation along with the $17 \mathrm{~ms}$ offset. The interpolation from nearby electrode was carried out to replace the bad channel. Meanwhile, the removal of artefacts was undertaken by targeting the ocular and movements artefacts. In the next step, the EEG data went through the averaging procedure at an individual level before data was combined all together which was subjected to baseline correction.

\section{E. Statistical Analysis}

The raw data of EEG was analysed by the EGI Net Station 5.3 software through several steps of extraction as mentioned in the section of EEG recording section. The analysis was carried out with all electrodes side from different regions pre-frontal (Fp1 and 2), frontal (F3-4, F7-8), temporal (T36), parietal ( $\left.\mathrm{P}_{3}-4\right)$, occipital (O1-2), central $\left(\mathrm{C}_{3}-4\right)$ and main central $(\mathrm{Pz}, \mathrm{Cz}, \mathrm{Fz})$ of $\mathrm{P} 300$ and $\mathrm{N} 2 \mathrm{OO}$ in order to explore the novelty of the cultural-related emotion processing of Malay culture among different nature of immigrant. In the next step, the ERP data were analysed with the Statistical Package for the Social Sciences (SPSS) Version 24. The analysis of variance (ANOVA) for a two-way mixed design was employed to determine the effect of immigrant status (four levels of between-subjects effect: (1) Malay - referral group, (2) Historical immigrant - Malaysian Chinese and Indian, (3) Current immigrant group 1 - i.e. immigrants living in Malaysia for a year and less, (4) Current immigrant group 2 i.e. immigrants living in Malaysia for more than a year) on the cultural-emotional processing as evoked by culture and nonculture visual stimuli (three levels of the within-subject effect: (1) Malay cultural heritage image, (2) Geometrical image, (3) Universal non-culture image.

\section{RESULT}

The analysis of variance (ANOVA) for a two-way mixed design was carried out in all side of electrodes in two major components - P300 and N200. Significant neuro-culture 
interaction was observed in the temporal area of the brain (T6 electrode) that is consistent in $\mathrm{P} 300$ [F $(1.94,225.43)=3.68$, p<0.01] and N2Oo [F $(5.8,224.18)=2.73, \mathrm{p}<0.05]$ (Table 4 and 5).

Further analysis of pairwise comparison (with effect size value as suggested by Cohen (1988) was carried out in T6P300 and T6-N20o to particularise the effect of groups (Malay, historical immigrants, current immigrants 1 and current immigrants 2) upon each stimulus (culture, geometry and non-culture), as depicted in Table 2 and 3 below:

Table 2. Pairwise comparison of different groups of immigrants in response to different categories of visual stimulus reflected in T6-p30o

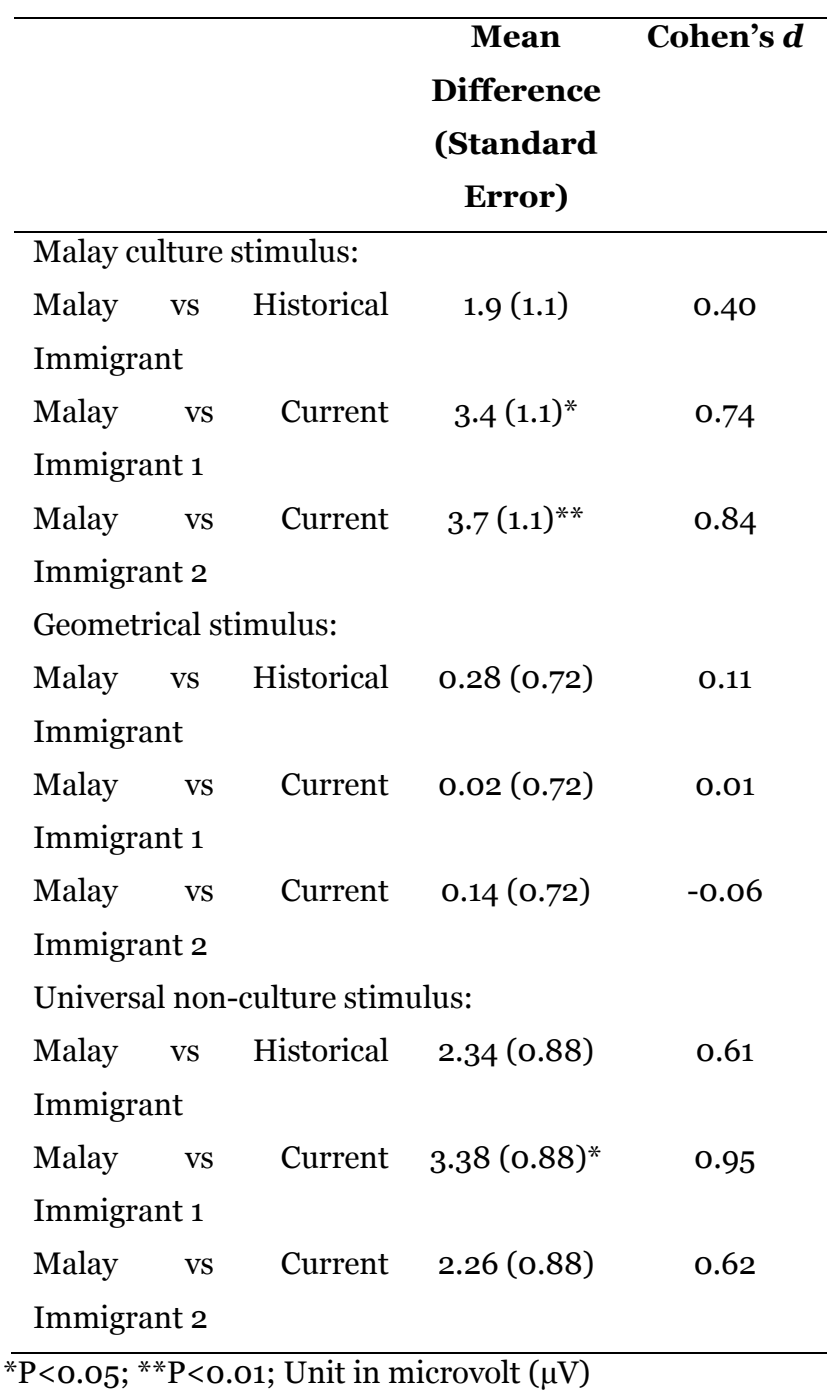

Table 3. Pairwise comparison of different groups of immigrants in response to different categories of visual stimulus reflected in T6-N200

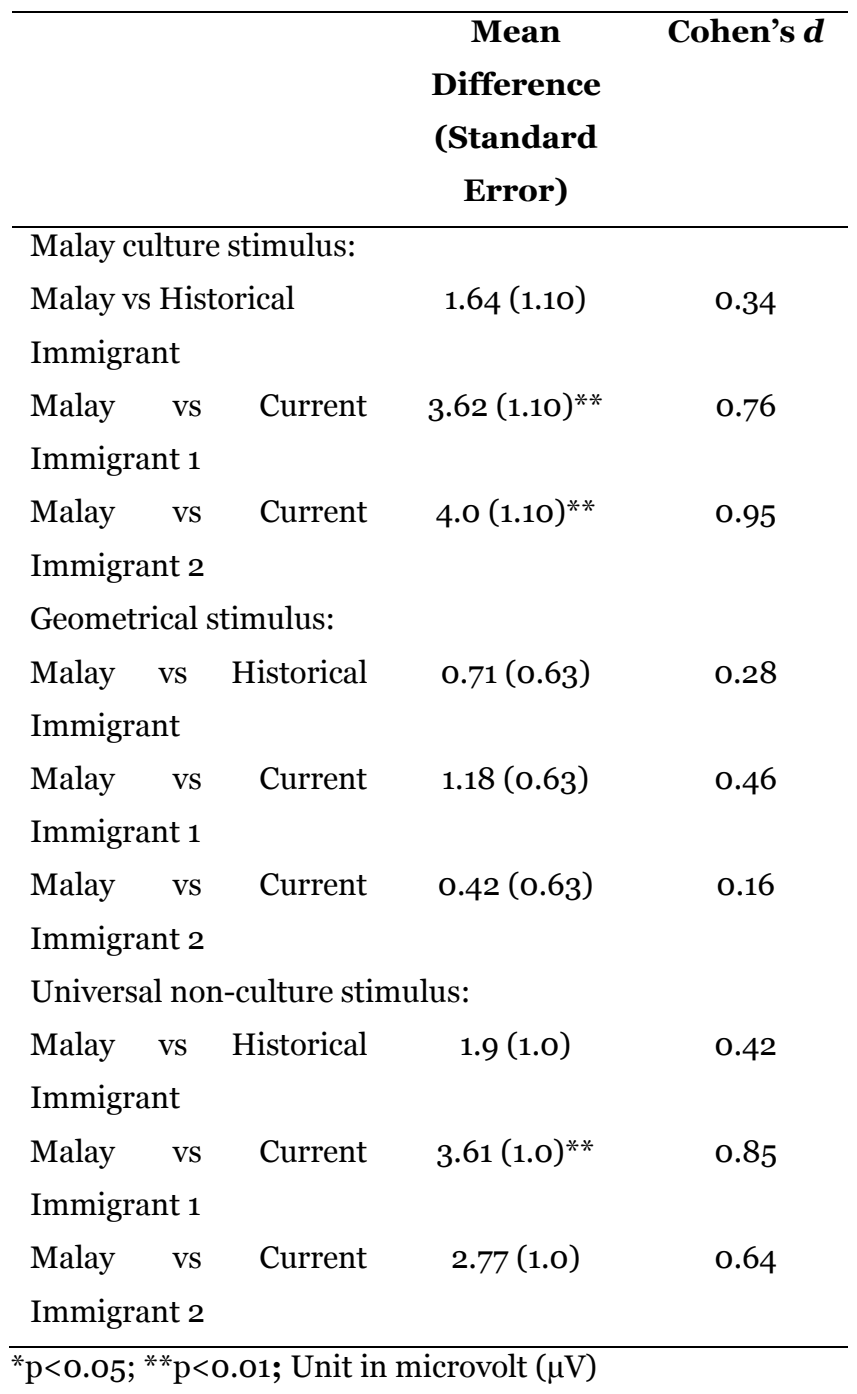


Table 4. Neuro-culture interaction of T6-P300 amplitude in different status of immigrant

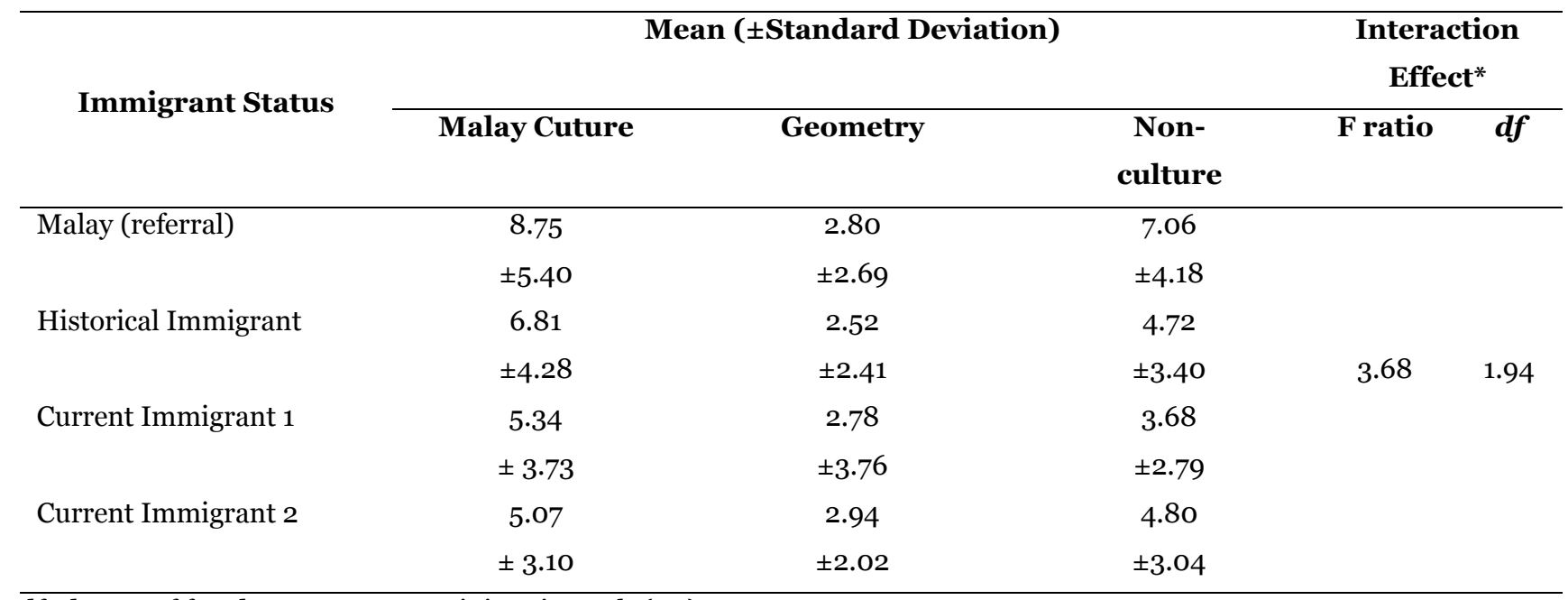

$\mathrm{df}=$ degree of freedom; ${ }^{*} \mathrm{p}<0.01$; Unit in microvolt $(\mu \mathrm{V})$

Table 5. Neuro-culture interaction of T6-N200 amplitude in different status of immigrant

\begin{tabular}{|c|c|c|c|c|c|}
\hline \multirow{2}{*}{ Immigrant Status } & \multicolumn{3}{|c|}{ Mean ( \pm Standard Deviation) } & \multicolumn{2}{|c|}{ Interaction Effect* } \\
\hline & Malay Cuture & Geometry & Non-culture & F ratio & $d f$ \\
\hline \multirow[t]{2}{*}{ Malay (referral) } & 9.09 & 3.57 & 7.83 & & \\
\hline & $\pm 5 \cdot 3$ & \pm 2.81 & \pm 5.04 & & \\
\hline \multirow[t]{2}{*}{ Historical Immigrant } & $7 \cdot 45$ & 2.85 & 5.96 & & \\
\hline & \pm 4.40 & \pm 2.29 & \pm 3.81 & & \\
\hline \multirow[t]{2}{*}{ Current Immigrant 1} & $5 \cdot 47$ & 2.39 & 4.22 & 2.73 & 5.8 \\
\hline & \pm 4.11 & \pm 2.32 & $\pm 3 \cdot 31$ & & \\
\hline \multirow[t]{2}{*}{ Current Immigrant 2} & 5.08 & 3.15 & 5.05 & & \\
\hline & \pm 2.81 & \pm 2.32 & \pm 3.50 & & \\
\hline
\end{tabular}

$\mathrm{df}=$ degree of freedom; * $\mathrm{p}<0.05 ;$ Unit in microvolt $(\mu \mathrm{V})$

Table 6. Reaction Time (RT) in Modified Oddball Paradigm of Event Related Potential

\begin{tabular}{|c|c|c|c|c|c|c|}
\hline & \multirow[t]{2}{*}{ M } & \multirow[t]{2}{*}{ HI } & \multirow[t]{2}{*}{ CI 1} & \multirow[t]{2}{*}{ CI 2} & \multicolumn{2}{|c|}{$\begin{array}{c}\text { One Way } \\
\text { ANOVA }\end{array}$} \\
\hline & & & & & F Ratio & $d f$ \\
\hline Malay cuture* & 702 & 731 & 786 & 847 & 9.20 & 3 \\
\hline (BUTTON 1) & \pm 117 & \pm 108 & \pm 113 & \pm 122 & & \\
\hline Non-culture* & 765 & 771 & 878 & 878 & 10.78 & 3 \\
\hline (BUTTON 2) & \pm 105 & \pm 110 & \pm 889 & \pm 117 & & \\
\hline
\end{tabular}

$\mathrm{df}=$ degree of freedom; *p<0.001

Reaction time: Participants pressed button ' 1 ' for Malay Culture and '2' for Universal Non-culture

CI 1=Current Immigrant- those living in Malaysia for a year and less; CI 2=Current Immigrant- those living in Malaysia for a more than a year; HI=Historical Immigrant; $M=$ Malay (referral) 
In culture stimulus T6-P30o (Table 2), Malay group indicated significant higher mean of amplitude in comparison to current immigrant 1 [mean difference $=3.4$, $\mathrm{SE}=1.09, \mathrm{p}<0.05]$ and current immigrant $2-$ [mean difference $=3.7, \mathrm{SE}=1.09, \mathrm{p}<0.01]$. This result was supported by medium to large effect size. However, the Malay group indicated non-significant differences in comparison with historical immigrant - [mean difference $=1.9$, se=1.09, ns]. Geometrical stimulus (non-emotional or control stimulus) T6-P300 exhibited non-significant differences of amplitude across the groups - Malay versus historical immigrant [mean difference $=0.28, \mathrm{SE}=0.72, \mathrm{~ns}]$, Malay versus current immigrant 1 [mean difference $=0.02$, se $=0.72, \mathrm{~ns}$ ], Malay versus current immigrant 2 [mean difference $=0.14, \mathrm{se}=0.72$, ns]. In universal non-culture stimulus T6-P30o, Malay group exhibited non-significant higher mean of amplitude than historical immigrant [mean difference $=2.34, \mathrm{SE}=0.88, \mathrm{~ns}$ ] and current immigrant 2 [mean difference $=2.26, \mathrm{SE}=0.88$, ns]. This is different from current immigrant 1 which indicated significant differences with the Malay group [mean difference $=3.38, \mathrm{SE}=0.88, \mathrm{p}<0.05]$, with large effect size.

In culture stimulus T6-N200 (Table 3), Malay group indicated significant higher mean of amplitude in comparison to current immigrant 1 [mean difference $=3.62$, $\mathrm{SE}=1.10, \mathrm{p}<0.01]$ and current immigrant 2 [mean difference=4.00, $\mathrm{SE}=1.10, \mathrm{p}<0.01]$. This result was supported by medium to large effect size. However, the Malay group indicated non-significant differences in comparison with historical immigrant - [mean difference=1.64, SE=1.10, ns]. Geometrical stimulus (nonemotional or control stimulus) T6-N200 exhibited nonsignificant differences of amplitude across the groups. Malay versus historical immigrant [mean difference $=0.71, \mathrm{SE}=0.63$, ns], Malay versus current immigrant 1 [mean difference $=1.18$, $\mathrm{se}=0.63$, ns], Malay versus current immigrant 2 [mean difference $=0.42, \mathrm{SE}=0.63, \mathrm{~ns}]$. In universal non-culture stimulus T6-N200, Malay group exhibited non-significant higher mean of amplitude than historical immigrant [mean difference $=1.87, \mathrm{SE}=1.03, \mathrm{~ns}]$ and current immigrant 2 [mean difference $=2.77, \mathrm{SE}=1.03, \mathrm{~ns}$ ]. This is different from current immigrant 1 which indicated a significant difference with the Malay group - [mean difference=3.61, SE=1.03, $\mathrm{p}<0.01]$, with large effect size.

The findings in Table 4 and 5 were supported by the pattern of behavioural data (i.e. reaction time) that indicated the significant differences of the reaction time across the groups, for the Malay culture $-F(3,116)=9.20, p<0.001)$ and universal non-culture - F $(3,116)=10.78, \mathrm{p}<0.001)$ (Table 6). When looking at the pairwise comparison analysis, the similar pattern of differences across the groups was maintained in which Malay group exhibited fastest reaction time than current immigrant 1 and current immigrant 2. This was different from historical immigrant which indicated nonsignificant differences with the Malay group.

\section{DISCUSSION}

In this study, we found the neuro-culture interaction (the interaction between the immigrant status and the neural substrate of the Malay cultural heritage) in the brain temporal area (T6) of the $\mathrm{P}_{300}$ and N20o components. Based on this interaction, there are two important patterns that we would like to highlight here. Firstly, historical Immigrants indicated similarity with majority ethnic (Malay) in their emotional reaction towards Malay culture stimulus, which was different from current immigrants 1 and 2 who did not exhibit similarity with Malay culture. Secondly, current immigrants 1 exhibited dissimilarity of their emotional reaction towards universal cultural stimulus in comparison to the majority ethnic (Malay) which was different from historical and current immigrants 2.

The $\mathrm{P}_{300}$ is a component that associated with the controlled evaluative process (Ito et al., 1998). Meanwhile, the N2Oo is a component that indexing the attention orienting response in an oddball task (Carretie et al., 2004). The role of the temporal area especially in interpreting the meaning of visual stimuli has been suggested by scholars (e.g., Schacter et. al., 2010; Smith, 2007; Verhoef et al., 2015) and were consistently significant at T6 in both components P300 and N200.

Our approach in this cultural study i.e. integrating neuroscience methodology in the study of culture, indeed, has given rich information in the area of emotion. Since we used the cultural-related emotional stimuli (i.e. the visualization of Malay cultural heritage images - Malay traditional dress, 
Malay traditional food, Malay traditional house and so on), thus, we could observe the variation in the processing of cultural-related emotion between different group of immigrants. This is in line with many studies surrounding neuro-emotion reporting the modulation of ERP component from the affective stimuli (Bayer \& Schacht, 2014; Olofsson


an ERP component that has been recognized as an important neural that underlying the process of emotion (Hajcak et al., 2010).

The dimension of emotion has been referred and explored widely in neuroscience field to understand the neural activity of the brain (LeDoux, 1998; Feng et. al., 2014; Yeo et al., 2019). In our study, the oddball paradigm was adopted in such a way (Malay culture, neutral, universal non-culture) in order to evoke the pattern of cultural-related emotion in different group of immigrants with the referral group of Malay ethnicity. From the pairwise comparison analysis, with regards to the emotional processing of cultural stimuli, it was observed that current immigrant (non-Malaysian) manifested the lowest $\mathrm{P} 300$ and N200 amplitude in temporal area (T6) when compared to historical immigrant (Malaysian Chinese and India) and referral group (Malay). In the meantime, historical immigrants (Malaysian Chinese and Indian) manifested lower $\mathrm{P}_{300}$ and $\mathrm{N} 200$ amplitude in temporal area (T6) when compared to referral group (Malay), but higher than the current immigrant (Non-Malaysian). These findings are in line with our hypothesis that the emotional reaction towards Malay cultural heritage stimuli is different between the three groups as mentioned above. Again, it is to stress that, (1) the current immigrant group exhibited LOWER emotional reaction towards the culture of new settlement (i.e. Malay culture) as compared to referral group (i.e. Malay). However, (2) the historical immigrant group exhibited SIMILAR emotional reaction with the Malay group in response towards the culture of the majority ethnic (i.e. Malay ethnicity). This findings in fact could be justified from the sociological point of view related to cultural mixing or known as acculturation in which acculturation is a concept in the field of sociology that refers to the process of shaping culture or identity of a specific ethnic group, formed due to the merging or the influence of other different cultures (BenShalom \& Horenczyk, 2003; Cote, 2006; Redfield et al.,
1936). A sociologist also stated that acculturation is a process of change in beliefs and practices when a cultural system of an ethnic group takes over another system of a different cultural group due to the encounter between two different cultures (Berry, 2005; Padilla \& Perez, 2003; Sam \& Berry, 2010). This fact clearly shows that the group of historical immigrants (Malaysian Chinese and Indian) gives a high emotional response on visualisation towards the Malay cultural heritage compared to the group of current immigrants (Non-Malaysian) because the group of historical immigrants (Malaysian Chinese and Indian) has treaded in Malaysia for centuries. This social group has experienced a process of acculturation between their culture and the Malay culture that has given an impact towards the development of both psychosocial and emotional domain. In other words, the cultural group of ethnic majority (i.e. Malay) has been absorbed to each and every aspect in the lives of the historical immigrants group (Malaysian Chinese and Indian) especially in the aspects of food, clothes, architecture and so on. Even then, it is found that this group of historical immigrants (Malaysian Chinese and Indian) still maintains some characteristics of their original culture even though they have gone through a very long process of acculturation. This scenario differentiates the group of historical immigrants (Malaysian Chinese and Indian) and the current immigrants (non-Malaysian).

The group of current immigrant is a group of nonMalaysian that is still at the stage of adapting. This fits the theory of 'contact and adaptation' that was proposed by Pearson (1987). Following this theory, before acculturation happens, the level of relationship or contact that follows through to adaptation are phases that a person with the experience of the phenomena of cultural encounter need to go through. The first level that is 'contact' is critical because it is a phase that refers to the relationship between different ethnic groups that is relatively important to minimize conflict. This 'contact' phase will give a stable situation among ethnic groups. Redfield et al. (1936) has asserted way earlier that acculturation happens when there are the characteristics of continuous contact among individuals in a different ethnic group and going on to cause a change in cultural pattern of one side of the ethnic group or both sides of the ethnic group that are involved. In addition, Redfield et 
al. (1936) also emphasized on 'direct contact' as an important element in acculturation. Thus, the group of current immigrants (non-Malaysian) is said of going through a process called adaptation (after going through the contact phase) before they are in a whole acculturation situation. Going through the emotional dimension in the context of acculturation, De Leersnyder (2017) has captured our attention that a group of minority immigrants undergoes a situation that involves the change of emotion due to the contact of a new culture. This context of emotional acculturation also emphasized that minorities newly acquired and heritage culture emotional patterns tend to co-exist.

The group of historical immigrants (Malaysian Chinese and Indian) and current immigrants (non-Malaysian) in fact has gone through a few phases of interaction as explained in the theory of neuro-culture interaction (Kitayama \& Thompson, 2010; Kitayama \& Uskul, 2011). During the first stage (that is the macro stage), factors like ecology, political and social system are macro factors that stand as a basis for the further process of neuro-culture interaction among immigrants. The primary thing that distinguishes the historical immigrant (Malaysian Chinese and Indian) and current immigrant (nonMalaysian) are the factor of difference between the age where the migration of the group of historical immigrant (Malaysian Chinese and Indian) has happened since centuries whereas the migration of the group of current immigrant (nonMalaysian) has just happened recently in these few years. This differences clearly shows that the difference of sociocultural and ecology differ between two ages.

In the next phase, the involvement of immigrants in cultural practice, from time to time has enabled a solid foundation that contributes to cultural survival. The group of historical immigrant (Malaysian Chinese and Indian) is a good example to explain about the cultural practice that has been across many generations and finally shaped a united culture in the same geographical area. Referring to Malaysian history, historical immigrants (Malaysian Chinese and Indian) at first are a group of immigrants who came to Tanah Melayu (Malaysia) on the reason of business and to work as labourers. From generation to generation, the product of marriage with the local people, they shaped a generation that practices a culture that is in line with the local people. As a process in acculturation, repeated or continuous cultural practice may produce significant impact on the neural connectivity in the brain system (Hanakawa et. al., 2003; Muente et. al., 2003; Maguire et al., 2000). This situation also happens to the group of current immigrant (nonMalaysian) in Malaysia. The difference is that the group of current immigrant (non-Malaysian) is still in the stage of 'adaptation' and need a longer time to see the impact on neural connectivity.

The changes in neural connectivity in the brain in fact is due to a cultural practice that is done continuously or repeatedly that causes the cultural behaviour to become a spontaneous or a volunteered cultural behaviour in the end. When cultural practices occur, the brain will influence the behaviour of a person from the inside (that is attention and thinking) and also outside (social behaviour). Thus, it can be said that the differences in the aspects of neural connectivity among the group of historical immigrant (Malaysian Chinese and Indian) dan current immigrant (non-Malaysian) are very high. In a long period, the cultural behaviour and its relationship with the neural connectivity of the brain can produce a positive impact towards social, economy and population growth (Kitayama \& Park, 2010; Kitayama \& Uskul, 2011).

Meanwhile, the trend of significant pattern of the universal non-culture stimulus indicated a slight difference from the Malay culture stimulus. Immigrant group 1 (i.e. living in Malaysia for less than a year) indicated significant lower emotional reaction than Malay group in response to universal non-culture stimulus. However, the difference was not seen in other comparisons (Malay versus historical immigrants; Malay versus Immigrants 2). This reasoning could be that the immigrant group 1 (as newcomers) were trying to put themselves in the host traditional environment, and because of that, at the same time, they paid 'less attention' to the universal culture in order to stabilize themselves while being in the 'contact' phase. Contact phase is the first phase from the three stages of acculturation (i.e. contact, adaptation, acculturation) as suggested by Pearson (1987). Immigrant group 1 were said to be in an unstable condition until they reach to the next phase - adaptation and acculturation. This pattern was different in other groups - Malay,_historical immigrants and immigrant group 2. Each group did not show significant difference between their emotional reaction 
towards Malay culture stimulus and Universal non-culture stimulus (however the difference of emotional reaction towards Malay culture stimulus was observed when comparison was made between these group). This pattern is believed in the way that, the modernization and urbanization has compensated their (Malay, historical immigrant and immigrant group 2) intrinsic feeling towards Malay culture stimulus and universal non-culture culture stimulus. Thus, these non-significant results in emotional response towards Malay culture stimulus and universal non-culture stimulus that were seen among Malay, historical immigrant and current immigrant group 2 could be justified from the influence of modernization in today's' life. The cultural trait has been claimed to be much affected along the process of modernization and urbanization (Gavrov \& Klyukanov, 2015; Kendall, 2007). It has also been claimed that the development of traditional society can be seen from the modern practices. We tend to see this finding as more inclined towards the theory of modernization as this theory is able to explain the social progress and development of societies (specifically to the question on 'why emotional reaction indicates similarity towards Malay culture stimulus and Universal non-malay stimulus in Malay, historical immigrant and current immigrant 2') and its interconnection with the psychosocial and socio-cultural changes (Mattison \& Sear, 2016). In sum, modernization has given impact to the psychosocial aspect of people life nowadays, however, based on this study's finding, modernisation indicates different impact on 'newcomer' or current immigrant group 1 as explained above.

Other than that, the significant neural process was not found at the midline electrode. This fact is justifiable as our study focus is different from some ERP studies especially in the area of personality and moral perception. These area of studies have found the significant $\mathrm{P}_{300}$ and N200 at midline electrodes (Yuan et al. 2012; Zhang et al., 2015). However, it is unjustifiable to compare these area of findings with our findings because our visual stimulus is different in its context.
We are looking at the context of 'culture mixing' between different socio-cultural groups. Thus, the different of the finding is possible. In addition, this study is novel (i.e, looking the neural substrate of Malay culture) and has never been done before and still need to be explored. As a reminder, these current findings should be taken in caution as the significant electrode was only seen at T6. Thus, more exploration is needed in future to establish the trend of finding in this cultural neuroscience area. Looking further the component of late positive potential (LPP) is also suggested by Hajcak et al., (2010) in order to understand the automatic processing of emotional stimuli in the cultural context.

\section{CONCLUSION}

The interaction of neural activity of the brain and its cultural environment is an important essence in neuro-culture interaction model that needs to be paid attention to. This essence directly explains the process of acculturation that has been undergone by the group of immigrants that has migrated to Malaysia, from the viewpoint of cultural neuroscience. The neuro-culture interaction model suggests that the neural connectivity system undergoes change due to the involvement in continuous cultural behaviour. This is clearly seen in the group of historical immigrants that has long treaded in Malaysia since the $17^{\text {th }}$ century. This fact also implies that long- and short-term exposure to cultural environment has important consequence in the psychological and biological system of people with different socio-cultural background.

\section{ACKNOWLEDGEMENT}

Ministry of Education, Malaysia (FRGS-203.ppsp.6171204) and Universiti Sains Malaysia Hospital.

\section{REFERENCES}

Andreassi, JL 2007, Heart activity and behavior II: stress, emotions, motivation, personality, social factors, brain interactions, and conditioning, Psychophysiology: human behavior and physiological response, $5^{\text {th }}$ edn, Mahwal, NJ: Lawrence Erlbaum Associates, Inc., Publishers. 
Bayer, M \& Schacht, A 2014, 'Event-related brain responses to emotional words, pictures, and faces across-domain comparison', Frontiers in Psychology, vol. 5, pp.1-10.

Beiser, M \& Hou, F 2017, 'Predictors of positive mental health among refugees: results from Canada's general social survey', Transcultural Psychiatry, vol.54, no. 5-6, pp. 675695.

Ben-Shalom, U \& Horenczyk, G 2003, 'Acculturation orientations: a facet theory perspective on the bidimensional model', Journal of Cross-Cultural Psychology, vol. 34, no. 2, pp. 176-188.

Berry, JW 2005, 'Acculturation: living successfully in two cultures', International Journal of Intercultural Relations, vol. 29, no. 6, pp. 697-712.

Breton F, Ritter W, Simson R \& Vaughan HG Jr 1988, 'The N2 component elicited by stimulus matches and multiple targets', Biological Psychology, vol. 27, pp. 23-44.

Carretié, L, Hinojosa, JA, Martin-Loeches, M, Merca-do, F \& Tapia, M 2004, 'Automatic attention to emotional stimuli: neural correlates', Human Brain Mapping, vol. 22, pp. 290299.

Cleary, SD, Snead, R, Dietz-Chavez, D, Rivera, I \& Edberg, MC 2018, 'Immigrant trauma and mental health outcomes among Latino youth', Journal of Immigrant and Minority Health, vol. 20, no. 5, pp. 1053-1059.

Cohen, J 1988, Statistical power analysis for the behavioural sciences, Hillsdale, NJ: Laurence Erlbaum Associates.

Cooper, S, Enticott, JC, Shawyer, F \& Meadows, G 2019, 'Determinants of mental illness among humanitarian migrants: longitudinal analysis of findings from the first three waves of a large cohort study', Frontiers in Psychiatry, vol. 10, pp. 545 .

Cote, JE 2006, 'Acculturation and identity: the role of individualization theory', Human Development, vol. 49, no. 1, pp. 31-35.

Curby, KM \& Moerel, D 2019, 'Behind the face of holistic perception: holistic processing of Gestalt stimuli and faces recruit overlapping perceptual mechanisms', Attention, Perception, \& Psychophysics, vol. 81, no. 8, pp. 2873-2880. doi: 10.3758/s13414-019-01749.

Daffner KR, Mesulam MM, Scinto LF, Calvo V, Faust R \& Holcomb PJ 2000, 'An electrophysiological index of stimulus unfamiliarity', Psychophysiology, vol. 37, pp. 737747.

De Leersnyder, J 2017, 'Emotional acculturation: a first review', Current Opinion in Psychology, vol. 17, pp. 67-73.
Department of National Heritage Malaysia 2020, Declaration of national heritage Malaysia 2015, viewed 1 June 2020, $<$ https://www.hrdnet.com.my/department-of-nationalheritage.html>.

Department of Statistic Malaysia 2010, Population and housing census of Malaysia, viewed 6 April 2020, <https://web.archive.org/web/20150301154300/http://w ww.statistics.gov.my/portal/download_Population/files/c ensus2010/Taburan_Penduduk_dan_Ciri

ciri_Asas_Demografi.pdf $>$.

Devaney, KJ, Rosen ML, Levin, EJ \& Somers, DC 2019, 'Identification of visual attentional regions of the temporoparietal junction in individual subjects using a vivid, novel oddball paradigm', Frontiers in Human Neuroscience, vol. 13, pp. 424.

Donchin, E \& Coles, MGH 1988, 'Is the P300 component a manifestation of context updating?', Behavioural Brain Science, vol. 11, pp. 357-374.

Duncan-Johnson CC \& Donchin E 1977, 'On quantifying surprise: the variation of event-related potentials with subjective probability', Psychophysiology, vol. 14, pp. 456467.

Dybala, MP, Butterfield, JK., Hendren-Santiago, BK \& Hara M 2020, 'Pancreatic Islets and Gestalt Principles', Diabetes, vol. 69, no. 9, pp. 1864-1874. doi: 10.2337/db2o0304.

Feng, C, Li, W, Tian, T, Luo, Y, Gu, R, Zhou, C \& Luo, YJ 2014, 'Arousal modulates valence effects on both early and late stages of affective picture processing in a passive viewing task', Social Neuroscience, vol. 9, no. 4, pp. 364-377.

Feldman, J 2001, 'Bayesian contour integration', Perception \& Psychophysics, vol 63, no. 7, pp. 1171-1182. doi.org/10.3758/BFo3194532.

Ferrari V, Bradley MM, Codispoti M \& Lang PJ 2010, 'Detecting novelty and significance', Journal of Cognitive Neuroscience, vol. 22, no. 4, pp. 404-411.

Gavrov, S \& Klyukanov, I 2015, 'Modernization, sociological theories of', ed. JD Wright in International Encyclopedia of the Social \& Behavioral Sciences Second Edition, Oxford, Elsevier.

Guberman, S 2017, 'Gestalt theory rearranged: back to Wertheimer', Frontiers in Psychology, vol. 11, no. 8, pp. 1782. doi: 10.3389/fpsyg.2017.01782.

Hajcak, G, MacNamara, A \& Olvet, DM 2010., 'Event-related potentials, emotion, and emotion regulation: an integrative review', Developmental Neuropsychology, vol. 35, no. 2, pp. 129-155. 
Hanakawa, T, Honda, M, Okada, T, Fukuyama, H \& Shibasaki, $\mathrm{H}$ 2003, 'Neural correlates underlying mental calculation in abacus experts: functional magnetic resonance imaging study', Neuroimage, vol. 19, pp. 296-307.

Ito, TA, Larsen, JT, Smith, NK \& Cacioppo, JT 1998, 'Negative information weighs more heavily on the brain: the negativity bias in evaluative categorizations', Journal of Personality and Social Psychology, vol. 75, pp. 887-900.

Kałamała, P, Sadowska, A, Ordziniak, W \& Chuderski, A 2017, 'Gestalt effects in visual working memory', Experimental Psychology, vol. 64, no. 1, pp. 5-13. doi: 10.1027/1618$3169 /$ aooo346.

Kendall, D (ed) 2007, Sociology in Our Times Sixth Edition, Belmont, Thomson/Wadsworth.

Kitayama, S \& Tompson, S 2010, 'Envisioning the future of cultural neuroscience', Asian Journal of Social Psychology, vol. 13, pp. 92-101.

Kitayama, S \& Uskul, A 2011, 'Culture, mind, and the brain: current evidence and future directions', Annual Review in Psychology, vol. 62, pp. 419-449.

Koffka, K (ed) 1935, Principles of gestalt psychology, New York, Harcourt Brace Jovanovich.

Kohler, W 1938, 'Physical Gestalten', eds WD Willis in A sourcebook of Gestalt psychology, London, Routledge and Kegan Paul.

LeDoux, JE (ed) 1998, The emotional brain: the mysterious underpinnings of emotional life, Simon \& Schuster, New York.

Maguire, EA, Gadian, DG, Johnsrude, IS, Good, CD, Ashburner, J, Frackowiak, RSJ \& Frith, CD 2000, 'Navigation-related structural changes in the hippocampi of taxi drivers', in Proceedings of the National Academy of Sciences of the United States of America, vol. 97, pp. 43984403.

Mattison, SM \& Sear, R 2016, 'Modernizing evolutionary anthropology: Introduction to the special issue', Human Nature, vol. 27, no. 4, pp. 335-350. doi: 10.1007/s12110016-9270-y.

Muente, TF, Nager, W, Beiss, T, Schroeder, C \& Altenmueller, E 2003, 'Specialization of the specialized: electrophysiological investigations in professional musicians', eds G Avanzini, C Faienza, D Minciacchi, L Lopez \& M Majno, in The neurosciences and music, New York Academy of Sciences, New York, pp. 131-139.

Naatanen, R \& Gaillard, AWK 1983, 'The orienting reflex and the N2 deflection of the event related potential (ERP)', eds AWK Gaillard \& W Ritter in Tutorials in event related potential research: endogenous components (10th edn), North Holland, Amsterdam, Netherlands.

Nichols, R, Moll, H \& Mackey, JL 2019, 'Rethinking cultural evolutionary psychology', Journal of Cognition and Culture, vol. 19, no. 5, pp. 477-492.

Olofsson, JK, Nordin, S, Sequeira, H \& Polich, J 2008, 'Affective picture processing: an integrative review of ERP findings' Biological Psychology, vol. 77, no. 3, pp. 247-265.

Othman, I (ed) 2002, Sejarah Malaysia (1800-1963), Utusan Publications, Kuala Lumpur, Malaysia.

Padilla, AM \& Perez, W 2003, 'Acculturation, social identity, and social cognition: A new perspective', Hispanic Journal of Behavioral Sciences, vol. 25, no. 1, pp. 35-55.

Persons, S (ed) 1987, Ethnic studies at Chicago: 1905-45, University of Illinois Pr, Urbana, US.

Polich, J 2007, 'Updating P300: An integrative theory of $\mathrm{P}_{3} \mathrm{a}$ and P3b', Clinical Neurophysiology, vol. 118, no. 10, pp. 2128-2148. doi: 10.1016/j.clinph.2007.04.019.

Redfield, R, Linton, R \& Herskovits, MJ 1936, 'Memorandum for the study of acculturation', American Anthropologist, vol. 38, pp. 149-152.

Rosenthal, $\mathrm{T}$ 2018, 'Immigration and acculturation: impact on health and well-being of immigrants', Current Hypertension Report, vol. 20, no. 8, pp. 70.

Sam, DL \& Berry JW 2010, 'Acculturation when individuals and groups of different cultural backgrounds meet', Perspectives on Psychological Science, vol. 5, no. 4, pp. 472. Schacter, D, Gilbert, DT, Wegner, DM 2010, Psychology, 2nd edn, Worth Publishers, New York, US.

Schupp, HT, Flaisch, T, Stockburger, J \& Junghofer, M 2016, 'Emotion and attention: event-related brain potential studies', Progress in Brain Research, vol. 156, pp. 31-51.

Shafie, F \& Zainudin, R (eds) 200o, Sejarah Malaysia, Penerbit Fajar Bakti Sdn. Bhd, Kuala Lumpur, Malaysia.

Smith K, 2007, Cognitive Psychology: Mind and Brain, Prentice Hall, New Jersey, US.

Squires KS, Petuchowski C, Wickens C, Donchin E 1977, 'The effects of stimulus sequence on event-related potentials: a comparison of visual and auditory sequences', Perception \& Psychophysics, vol. 22, pp. 31-40.

Sun, Q, Geeraert, N \& Simpson, A 2020, 'Never mind the acculturation gap: migrant youth's wellbeing benefit when they retain their heritage culture, but their parents adopt the settlement culture', Journal of Youth and Adolescent, vol. 49, no. 2, pp. 520-533. 
Snyder E, Hillyard SA 1976, 'Long-latency evoked potentials to irrelevant, deviant stimuli', Behavioral Biology, vol. 16, pp. 319-331.

Telzer, EH, Yuen, C, Gonzales, N \& Fuligni, AJ 2016, 'Filling gaps in the acculturation gap-distress model: heritage cultural maintenance and adjustment in MexicanAmerican families', Journal of Youth and Adolescent, vol. 45, no. 7, pp. 1412-1425.

Ubaithulla (ed) 2001, Namathu Nadu Nam Makkal: Malaysia, Ubaidi Foundation, Kuala Lumpur, Malaysia.

Urzua, A, Ferrer, R, Canales GV, Nunez, AD, Ravanal, LI \& Tabilo, PB 2017, 'The influence of acculturation strategies in quality of life by immigrants in Northern Chile', Quality of Life Research, vol. 26, pp. 717-726.

Vareka, L, Bruha P \& Moucek R 2014, 'Event-related potential datasets based on a three-stimulus paradigm', Gigascience, vol. 3, pp. 35 .

Verhoef BE, Bohon, KS \& Conway, BR 2015, 'Functional architecture for disparity in macaque inferior temporal cortex and its relationship to the architecture for faces, color, scenes, and visual field, Journal of Neuroscience, vol. 35, no. 17, pp. 6952-6968.

Woodman, GF 2010, 'A brief introduction to the use of event related potentials (ERPs) in studies of perception and attention'. Attention, Perception and Psychophysics, vol. 72, pp. 1-16.

Yeo, D, Kim, H, Her, S, Choi, JW, Cha, KS \& Kim, KH 2019, 'Spatiotemporal analysis of event-related current density reveals dissociable effects of arousal and valence on emotional picture processing', Journal of Korean Medical Science, vol. 34, no. 20, pp. 146-155

Yuan, J, Zhang, J, Zhou, X, Yang, J, Meng, X, Zhang, Q \& Li, $\mathrm{H}$ 2012, 'Neural mechanisms underlying the higher levels of subjective well-being in extraverts: pleasant bias and unpleasant resistance', Cognitive, Affective, \& Behavioral Neuroscience, vol. 12, no. 1, pp. 175-192.

Yusoff, N, Samsuri, N, Ayob, S, \& Reza, F 2019, 'Visualization of Malay traditional food: emotional expression of the immigrants in Malaysia', GeoJournal of Tourism and Geosites, vol. 26, no. 3, pp. 905-915.

Zainal Abidin, ZH, Habidin, NF, Yusof MY, Hassan, P, Yaacob, HR, Yaacob, M \& Noh, AM 2016, 'Assimilation of the Malay culture towards the Straights of Chinese Community in the state of Kelantan: study in Kampung Pasir Parit, Chetok, Pasir Mas, Kelantan', International Journal of Academic Research in Business and Social Sciences, vol. 6, no. 11, pp. 38-51.
Zhang X, Guo Q, Zhang Y, Lou L, Ding D 2015, 'Different timing features in brain processing of core and moral disgust pictures: an event-related potentials study', PLoS ONE, vol. 10, no. 5, pp. eo128531. 